\title{
Intracellular inclusion bodies in 14 patients with B cell lymphoproliferative disorders
}

\author{
O PETERS, C THIELEMANS, L STEENSSENS, M DE WAELE, W HiJMANS, * \\ B VAN CAMP
}

From the Department of Hematology, University of the Free University, Brussels, *Study Group for Medical Gerontology, Department of Pathology, University of Leiden

SUMmaRY Two types of intracytoplasmic inclusion were detected by immunofluorescence microscopy in 12 patients with chronic lymphocytic leukaemia and two patients with a leukaemic phase of well differentiated lymphocytic lymphoma. Further analysis with light- and electron microscopy, showed that most inclusion bodies were rod-like crystalline structures. However, in three patients they consisted of amorphous vesicular precipitates.

Immunological studies revealed the presence of immunoglobulins of the same class and type at the cell surface as well as in the inclusion bodies. The monoclonal immunoglobulins were all of lambda type except in two cases. The origin of immunoglobulin inclusion bodies in B cell malignancies is discussed in relation to published data and our own observation in one patient followed during treatment.

B chronic lymphocytic leukaemia (CLL) and lymphocytic lymphomas can in general be regarded as a neoplastic proliferation of B lymphocytes "frozen" at an immature maturation stage, characterised by the presence of surface immunoglobulins only. ${ }^{1}$

As B lymphocytes, early in their differentiation, get committed to the synthesis of an $\mathrm{Ig}$ with an unique $\mathrm{V}_{\mathrm{H}}-\mathrm{V}_{\mathrm{L}}$ region-ie idiotype-associated with a single light chain isotype, ${ }^{2}$ a malignant $\mathrm{B}$ cell transformation will give rise to a malignant clone of cells each carrying identical properties when compared to the original transformed cell.

It follows that in one patient all malignant B cells synthesise identical Ig molecules. Although multiple heavy chain classes can be expressed on the same cell, the exclusive expression on one light chain isotype can be used as a criterion for monoclonality, while the idiotype has to be regarded as a tumour specific marker. ${ }^{3}$

Several reports on patients with B-CLL have indicated that the malignant lymphocytes of some CLL patients manifest intracytoplasmic inclusion bodies consisting of monoclonal immunoglobulins. These intracytoplasmic inclusions have been ob-

Accepted for publication 5 October 1983 served in about $3-7 \%$ of all CLL patients, ${ }^{+7}$ depending on the technique used. Immunofluorescence microscopy seems the most sensitive method for their detection. Most of these inclusions, are of IgM lambda nature, ${ }^{4-12}$ but isolated cases are reported expressing IgM kappa, ${ }^{13}$ IgA lambda, ${ }^{5-14}$ IgG kappa ${ }^{15}$ or lambda light chain only.$^{16}$ In each case the surface immunoglobulin is identical to the one found in the inclusion bodies. Similar inclusion bodies have been demonstrated in lymphoproliferative disorders other than CLL, such as mixed lymphocytichistiocytic lymphoma, ${ }^{17}$ immunoblastic lymphoma ${ }^{18}$ and multiple myeloma. ${ }^{19}$

In our laboratory B-lymphoproliferative diseases are routinely investigated for the presence of intracellular immunoglobulins by immunofluorescence microscopy. In this way intracellular inclusions were found in 14 patients. Two different types of intracytoplasmic inclusions were observed. In most of the 14 patients the inclusions had a rod-like structure, in only three patients we observed a globular structure. On no occasion were both types of inclusions present simultaneously in the same patient. The inclusion bodies of seven patients were studied by electron microscopy. The presence of Ig containing crystals was followed in one patient during chlorambucil treatment and will be discussed in more detail. 


\section{Material and methods}

PATIENTS

The cytoplasmic inclusions were detected by a systematic examination of the peripheral blood of patients with a B-lymphoproliferative disorder, using anti-immunoglobulin sera and cytoplasmic immunofluorescence microscopy. Further immunological and morphological studies were then carried out. The diagnosis of chronic lymphocytic leukaemia in 12 patients with intracytoplasmic inclusion bodies was made on the basis of chronic peripheral lymphocytosis $\left(>4000 \mathrm{~mm}^{3}\right)$ combined with infiltration of the bone marrow ( $>40 \%$ lymphocytes). Patients were allocated to one of the five anatomicoclinical stages as proposed by Binet et al: ${ }^{20}$ five patients belonged to stage 1 and six patients to stage 3 , whereas the initial clinical findings were not available in one patient. In two other patients, intracytoplasmic inclusion bodies were seen during the leukaemic phase developing several years after the initial diagnosis of well differentiated lymphocytic lymphoma (WDLL).

IMMUNOFLUORESCENCE STUDIES

Surface immunoglobulin (sIg)

Peripheral blood mononuclear cells are isolated by Ficoll-Hypaque centrifugation of venous EDTA blood. Cells recovered from the interface are washed three times in phosphate-buffered saline (PBS), containing $1 \%$ bovine serum albumin (PBS-BSA) at $\mathrm{pH} 7 \cdot 2$. A suspension of $30 \times 10^{6} \mathrm{cells} / \mu \mathrm{l}$ is made. To allow shedding of cytophilic Ig, the mononuclear cell suspension is incubated for two hours at $37^{\circ} \mathrm{C}$ in a $5 \%$ BSA solution. In order to inactivate the Fc receptors of the so-called undefined mononuclear cells prefixation with paraformaldehyde $0.04 \%$ is performed for $10 \mathrm{~min}$ at room temperature..$^{21}{ }^{22}$ Surface immunoglobulin positive lymphocytes in the mononuclear cell suspension are assessed using monospecific antihuman Ig antisera conjugated to FITC or TRITC. Detailed specifications have been published. ${ }^{23}$ After a thorough washing procedure, the cells are mounted on microscopical slides in buffered glycerol and sealed. All preparations are viewed using a Leitz Dialux ${ }^{\circledR}$ Ploem Opak fluorescence microscope, equipped for the two wavelengths method with simultaneous use of phase contrast optics for the morphological identification of the cells. The percentage of lymphocytes having sIg determinants is determined.

\section{Cytoplasmic immunoglobulins (cIg)}

A washed suspension of approximately $1.5 \times 10^{6}$ peripheral blood mononuclear cells per $\mathrm{ml}$ is sedimented by a cytocentrifuge as described earlier. ${ }^{24}$ Staining is performed by incubation of the fixed and washed slides with the same conjugated antisera as used for sIg staining.

The cIg positive cells are counted. Their number is expressed as a percentage of the lymphocytes present in the preparations.

LIGHT MICROSCOPY

Blood smears were stained with May-GrünwaldGiemsa and periodic acid-Schiff reagent (PAS).

\section{ELECTRON MICROSCOPY}

Lymphocyte preparations are fixed at room temperature for one hour in $2.5 \%$ glutaraldehyde in $0.075 \mathrm{M}$

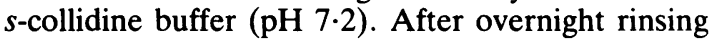
with $0.2 \mathrm{M} s$-collidine buffer, the cells are fixed for one hour in $1 \%$ unbuffered osmium tetroxide. Prior to dehydration they are stained with $0.5 \%$ uranyl acetate at $\mathrm{pH} 5 \cdot 3$ for one hour. They are embedded in Spurr resin. Ultrathin sections are contrasted with lead citrate and examined with transmission electron microscopy.

\section{Results}

Fourteen patients, expressing intracellular inclusion bodies detected by cytoplasmic immunofluorescence microscopy, were studied. The surface immunoglobulins (sIg) and the immunoglobulin content of the intracellular inclusions in 14 patients are summarised in the Table. In two cases (Cre and Sch) the sIg expression was not determined, in one case (Vho) no sIg was detectable. In 10 of the remaining 11 patients, the sIg's belonged to the lambda light chain type and the kappa light chain type was only seen once. The IgM heavy chain was seen in 10 cases and in two of them IgD was expressed simultaneously. One patient carried sIgA only. In all cases the fluorescence intensity of the surface immunoglobulin was faint and often only a few sIg positive cells could be visualised. In contrast, the inclusions exhibited a bright fluorescence staining while the surrounding cytoplasm was negative. It is important to note that immunoglobulin expression of the inclusion bodies was identical to the one found at the surface level, except in two cases (Vdu and Vke) where no IgD was found in the crystals. Finally, one patient (Vho) presented with IgG kappa inclusions without visible surface immunoglobulins. Details of this exceptional case, will be published elsewhere.

Often multiple inclusion bodies were noticed in one lymphocyte. The number of lymphocytes containing inclusions was always lower than the amount of sIg bearing lymphocytes, with again case Vho as the exception. It is interesting to note that the percentage of inclusion containing lymphocytes ranged from 1 to $54 \%$. The morphological appear- 
Morphological and immunofluorescent study of peripheral blood lymphocytes

\begin{tabular}{|c|c|c|c|c|c|c|}
\hline \multirow[t]{2}{*}{ Patients } & \multirow[t]{2}{*}{ Sex } & \multirow[t]{2}{*}{$A g e(y r)$} & \multicolumn{4}{|c|}{ Immunofluorescence } \\
\hline & & & Morphology & $\begin{array}{l}\text { \% inclusion } \\
\text { positive } \\
\text { lymphocytes }\end{array}$ & $\begin{array}{l}\text { Inclusion } \\
\text { Ig type }\end{array}$ & $\begin{array}{l}\text { Predominant } \\
\text { surface Ig }\end{array}$ \\
\hline $\begin{array}{l}\text { Cla } \\
\text { Vha } \\
\text { Cre } \\
\text { Sch } \\
\text { Buy } \\
\text { Lau } \\
\text { Vho } \\
\text { Vdu } \\
\text { Gee } \\
\text { Goo } \\
\text { Vke } \\
\text { Bie } \\
\text { Dvo } \\
\text { Dwi } \\
\end{array}$ & $\begin{array}{l}\mathbf{M} \\
\mathbf{F} \\
\mathbf{M} \\
\mathbf{M} \\
\mathbf{M} \\
\mathbf{M} \\
\mathbf{F} \\
\mathbf{M} \\
\mathbf{M} \\
\mathbf{F} \\
\mathbf{M} \\
\mathbf{F} \\
\mathbf{M} \\
\mathbf{F} \\
\end{array}$ & $\begin{array}{l}72 \\
83 \\
68 \\
53 \\
66 \\
60 \\
70 \\
48 \\
49 \\
82 \\
73 \\
56 \\
68 \\
56 \\
\end{array}$ & $\begin{array}{l}\text { Rod-like } \\
\text { ", } \\
\text { ", } \\
\text { ", } \\
\text { G̈lobular } \\
\text { " } \\
\text { R̈od-like } \\
\text { ", } \\
\text { ", }\end{array}$ & $\begin{array}{r}54 \\
6 \\
15 \\
3 \\
3 \\
1 \\
40 \\
3 \\
8 \\
41 \\
3,5 \\
44 \\
3 \\
4 \\
\end{array}$ & $\begin{array}{l}\text { Iga- } \lambda \\
\text { IgM- } \lambda \\
\text { IgM- }-\lambda \\
\text { IgM- }-\lambda \\
\text { IgM- }-\lambda \\
\text { IgM- }-\lambda \\
\text { IgG- } \lambda \\
\text { IgM- }-\lambda \\
\text { IgM- }-\lambda \\
\text { IgM- }-\lambda \\
\text { IgM- }-\lambda \\
\text { IgM- }-\kappa \\
\text { IgM- }-\lambda \\
\text { IgM- }-\lambda\end{array}$ & $\begin{array}{l}\text { IgA- } \lambda \\
\text { IgM- } \lambda \\
\text { Not done } \\
\text { Not done } \\
\text { IgM- } \lambda \\
\text { IgM- } \lambda \\
\text { Absent } \\
\text { IgM-D- } \lambda \\
\text { IgM- } \lambda \\
\text { IgM- } \lambda \\
\text { IgM-D- } \lambda \\
\text { IgM- } \lambda \\
\text { IgM- } \lambda \\
\text { IgM- } \lambda\end{array}$ \\
\hline
\end{tabular}

ance of most inclusion bodies was needle-like, while in three cases (Vdu, Gee and Goo) they had rather a globular structure. Both types of inclusions were never seen simultaneously in one patient. In MayGrünwald-Giemsa stained peripheral blood films intracellular inclusion bodies were found in the lymphocytes of six out of the 14 patients (Cla, Cre, Vho, Gee, Goo, Bie). In most cases they appeared as large, unstained rectangular structures (Fig. 1a), while in others they presented as small globular vesicles (Fig. 1b). Some lymphocytes contained multiple inclusions of the same type. The inclusions were PAS-negative. In seven patients the ultrastructural features of these inclusion bodies were studied by electron microscopy. The morphological characteristics of medium-sized lymphocytes with a relative abundance of free ribosomes were confirmed. As already suspected by light and immunofluorescence microscopy, two types of inclusions could be distinguished. In cases Cla, Vha, Cre and Vho the inclusions appeared as electron dense crystalline structures, consisting of laminar material on longitudinal section, with a periodicity of 40 to $60 \AA$,

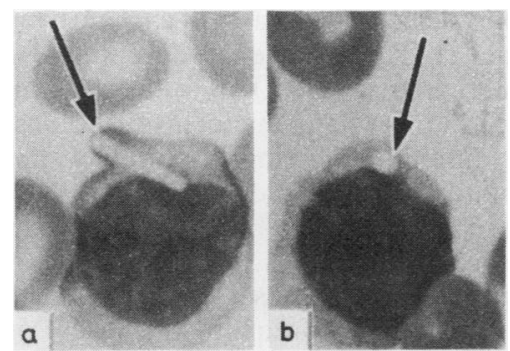

Fig. 1 (a) and (b) Light microscopic aspect of the two types of intracytoplasmic inclusions. In May-GrünwaldGiemsa stained peripheral blood smears the intracytoplasmic inclusions appeared as (a) unstained rod-like (arrow) or (b) globular structures (arrow) $\times 1140$. surrounded by rough endoplasmic reticulum (Figs. 2, 3). The lymphocytes of cases Vdu, Gee and Goo had pronounced dilatation of endoplasmic reticulum,

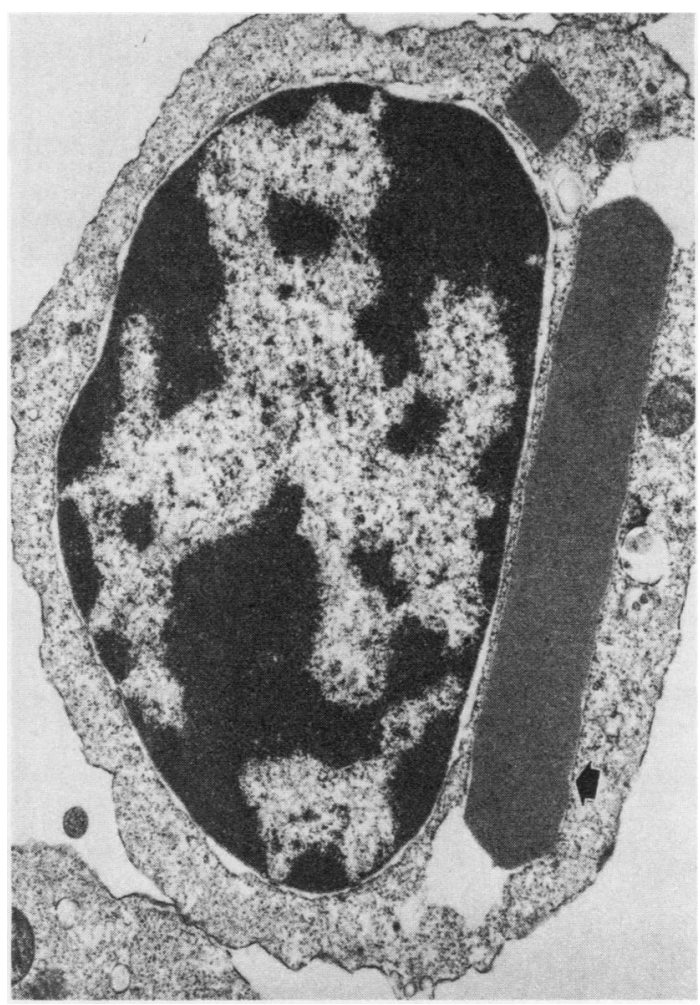

Figs. 2, 3, 4, 5 Electron microscopic aspect of the two types of intracytoplasmic inclusions. The rod-like inclusions (Figs. 2, 3 arrow) showed a crystalline structure surrounded by endoplasmic reticulum, while the globular inclusions were formed by dilated strands of rough endoplasmic reticulum containing an amorphous material (Figs. 4, 5 arrow). 


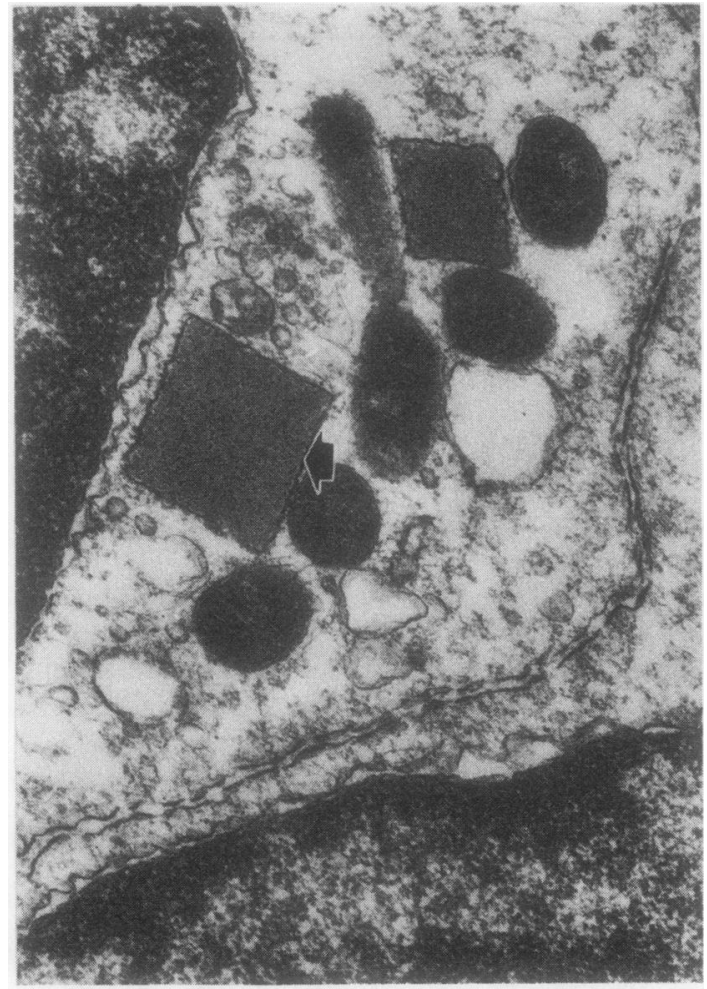

Fig. 3

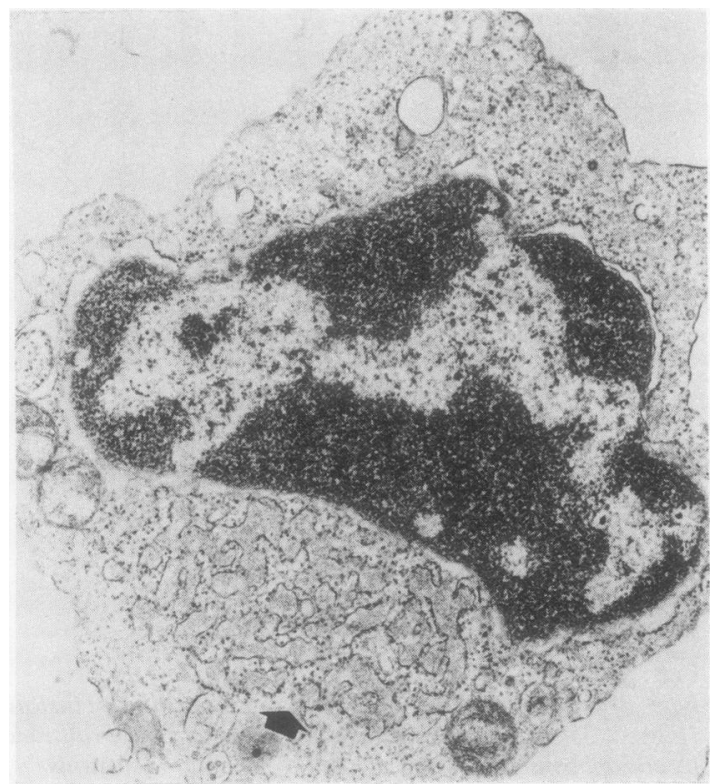

Fig. 4

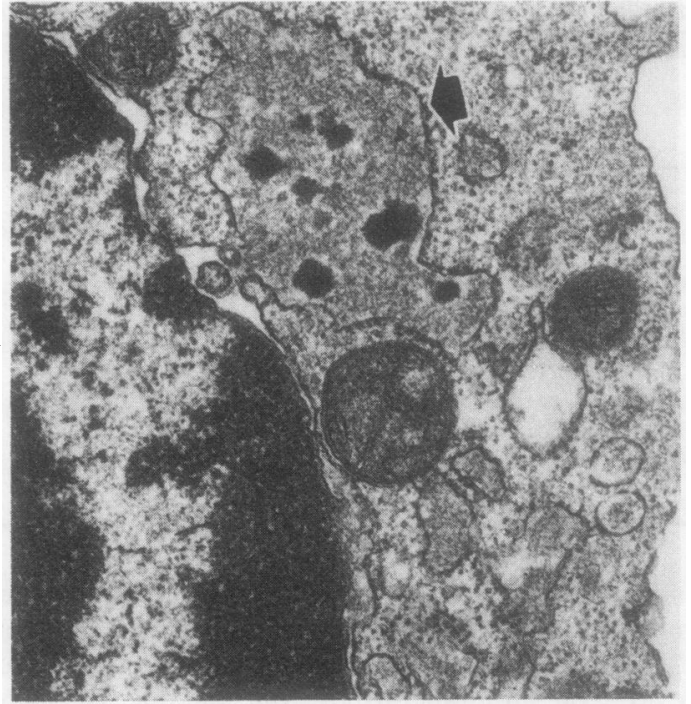

Fig. 5

containing an amorphous material without evident periodicity (Figs. 4, 5).

To evaluate the relation between inclusion positive lymphocytes and surface immunoglobulin positive lymphocytes, both cell subtypes were examined several times during the course of a chlorambucil treatment in one patient (Cla). Fig. 6 indicates that before treatment the peripheral blood lymphocyte count was $58000 \mathrm{~mm}^{3}$, of which $55 \%$ expressed sIgAlambda and $50 \%$ had crystalline inclusions. After treatment the lymphocyte count was near to normal. However, during a relapse the sIg positive lymphocytes increased again up to $43 \%$ while the relative numbers of crystal positive cells remained very low.

\section{Discussion}

This report deals with 14 cases of chronic lymphocytic leukaemia (CLL) and well differentiated lymphocytic lymphoma (WDLL) in which the malignant cells were shown to contain inclusion bodies consisting of immunoglobulins as demonstrated by immunofluorescence and electron microscopy.

In the last decade a number of reports have appeared describing this anomaly ${ }^{5-19}{ }^{25-28}$ in B cell lymphoproliferative diseases of which CLL forms the large majority. The frequency of these inclusion bodies depends on the morphological techniques used, but can be estimated to be about $5 \%$ of all CLL patients. In this context, the intracytoplasmic immunofluorescence staining seems to be the most sensitive method. This technique confirmed the Ig 


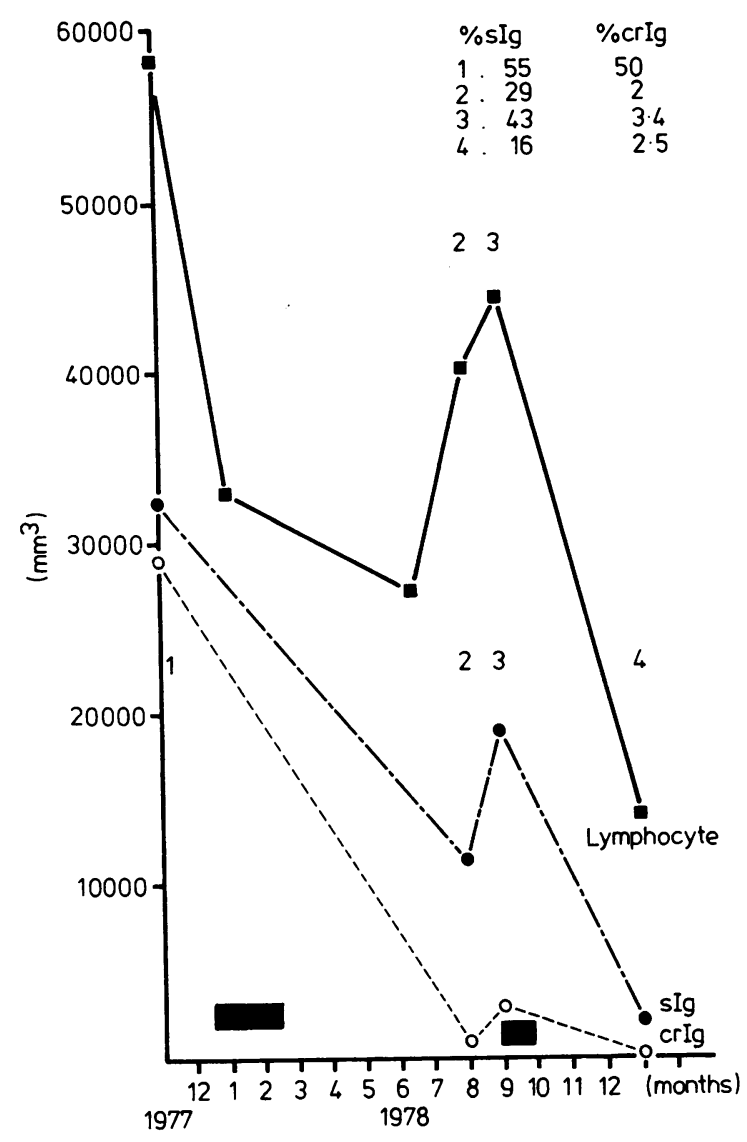

Fig. 6 Evolution of lymphocytosis during treatment of patient (Cla): surface Immunoglobulin positive (sIg) and crystalline Immunoglobulin containing (crIg) lymphocytes are plotted in absolute number $\left(\mathrm{mm}^{3}\right)$; Leukeran ( was given on two occasions.

content with a monoclonal restriction comparable to the sIg of these inclusion positive cells. In this study two morphologically distinct types of inclusion body were observed. The majority ố reports describe rodlike crystalline structures which by electron microscopy examination were proven to consist of laminar material with a periodicity of 40 to $60 \AA$, surrounded by endoplasmic reticulum..$^{5912}$ Recently,,$^{15}$ two reports were published describing a few CLL patients presenting oval shaped inclusions of amorphous material resembling Russell bodies. Guglielmi et a ${ }^{28}$ demonstrated by immuno-electron microscopy that these inclusion bodies consisted of amorphous material surrounded by dilated rough endoplasmic reticulum. Although we did not use their immunological method a similar observation was made in our cases Vdu, Gee and Goo.
As already stated, the immunoglobulin content of both types of inclusion body displayed an identical heavy and light chain restriction to the one present at the surface of the malignant cells.

However, in this context it is important to note that the additional delta chain at the surface of the malignant cells of two patients was not found in the cytoplasmic inclusions. This finding was also noted in the study of Guglielmi $e t a^{p 8}$ and is comparable to findings seen in morbus Waldenström ${ }^{29}{ }^{30}$ and CLL associated with monoclonal immunoglobulins. ${ }^{31}{ }^{33} \mathrm{In}$ view of our current knowledge on cellular immunoglobulin synthesis ${ }^{34}$ the former observation indicates that the Ig content of the inclusion bodies is derived from the secretion m-RNA. Indeed, during maturation of the B lymphocyte towards the secreting B cell (ie plasma cell) IgD is lost from the surface. ${ }^{35}$ This suggests that CLL cells containing this type of inclusion body are more advanced in their maturation level and more closely related to the cells secreting a paraprotein, as is observed in about $5 \%$ of all CLL patients. ${ }^{36} \mathrm{It}$ is unclear why the secretory Igs are precipitated in the cytoplasm. This phenomenon could be due to the inability of the Golgi apparatus to add the essential carbohydrate residues for secretion of the Ig. ${ }^{37}$ This hypothesis is supported by the PAS negativity of the inclusion bodies seen in all our patients. It is intriguing that in most of the patients reported by others and ourselves the inclusion bodies contain lambda light chain. This is in contrast to the predominance of kappa light chain on the cell surface membrane in B-CLL patients. ${ }^{35}$ Biosynthetic stu$\operatorname{dies}^{14}{ }^{15} 38$ have shown that monoclonal Ig chains could accumulate and precipitate as crystals due to unusual physicochemical properties, possibly linked to the intracellular environment. It could be hypothesised that lambda light chain possesses such properties.

Finally, the evolution of the percentage of sIg positive and crystal positive lymphocytes of case $\mathrm{Cla}$, during chlorambucil treatment, reflects a different drug sensitivity within the malignant $B$ cell clone (Fig. 6). Only after a certain lapse of time the B cells will accumulate intracellular Ig, which then will precipitate as inclusion bodies. Another possibility could be that the secretory properties of the malignant $B$ cells are affected by chorambucil. In any case, the final prognosis of patients with CLL and inclusion bodies, does not seem to differ from that of classical CLL. This was proven by the fact that all our $12 \mathrm{CLL}$ patients could be classified from stage I to stage $\mathrm{V}$ of the anatomicoclinical classification proposed by Binet et al. ${ }^{20}$ The clinical evolution of these patients was similar to that seen in other CLL patients.

The authors wish to thank Professor FJ Cleton and 
Dr G Den Ottolander. This study was sponsored by grant NFWO No 3.0041.81 and No 3.0076.83. Dr C Thielemans has a Fulbright/Hays travel grant. This paper was partly a result of intensive discussions within the "EURAGE" EEC concerted action programme on ageing.

\section{References}

${ }^{1}$ Preud'homme JL, Seligmann M. Surface bound immunoglobulins as a cell marker in human lymphoproliferative diseases. Blood 1972;40,6:777-94.

${ }^{2}$ Vogler LB. Bone marrow B-cell development. Clin Hematol 1982;11(3):509-29.

${ }^{3}$ Kunkel HG. Surface markers of human lymphocytes. Behring Institute Mittling 1976;59:1.

${ }^{4}$ Chen YH, Heller P. Lymphocyte surface immunoglobulin density and immunoglobulin secretion in vitro in chronic lymphocytic leukemia. Blood 1978;52(2):601-8.

${ }^{5}$ Cawley JC, Smith J, Goldstone AH, Emmines JN, Hamblin J, Hough L. IgA and IgM cytoplasmic inclusions in a series of cases of chronic lymphocytic leukemia. Clin Exp Immunol 1976;23:78-82.

${ }^{6}$ Flandrin G, Hurez D, Preud'homme JL, Binet JL, Seligmann M. Leucemie lymphoide chronique a cristaux avec macroglobine monoclonale intracellulaire non excretée. Nouv Rev Fr Hematol 1971;11:422-8.

${ }^{7}$ Feremans WW, Neve P, Coudron M. IgM lambda cytoplasmic crystals in three cases of immunocytoma: a clinical cytochemical and ultrastructural study. J Clin Pathol 1978;31:250-8.

${ }^{8}$ Clark C, Rydell RE, Kaplan ME. Frequent association of IgM lambda with crystalline inclusions in chronic lymphatic leukemic lymphocytes. N Engl J Med 1973;289:113-7.

${ }^{9}$ Hurez D, Flandrin G, Preud'homme JL, Seligmann M. Unreleased intracellular monoclonal macroglobulin in chronic lymphocytic leukemia. Clin Exp Immunol 1972;10:223-34.

${ }^{10}$ Roberts GH, Gordon J, Smith JL, Newell D, Pike R. Biosynthesis and characterisation of IgM-lambda in a case of chronic lymphocytic leukemia with intracellular immunoglobulin inclusions. J Clin Pathol 1979;32:271-9.

${ }^{11}$ Kaplan ME, Clark C, Rydell RE. Crystalline IgM inclusions in CLL lymphocytes. Clin Res 1972;20:787.

12 Kaplan ME, Rydell RE, Clark C. Crystalline IgM cytoplasmic inclusions in chronic lymphocyte leukaemic lymphocytes: a new syndrome? J Clin Invest 1973;52:45.

${ }^{13}$ Smith JL, Gordon J, Newell DG, Whisson M. The biosynthesis and characterisation of unreleased IgM in a case of CLL. Br J Haematol 1977;37:217-22.

${ }^{14}$ Gordon J, Smith JL. Characterisation of a secretory block in a case of CLL with IgA lambda crystalline inclusions. $\mathrm{Br} \mathrm{J}$ Haematol 1979:43:155-8.

${ }^{15}$ Mies KM, Marshall J, Oberlin MA, Halpern MS, Brown JC. Chronic lymphocytic leukaemia with gamma chain cytoplasmic inclusions. Am J Clin Pathol 1976;65:948-56.

${ }^{16}$ McCann SR, Whelan A, Greally J. Intracellular lambda light chain inclusions in chronic lymphocytic leukemia. $B r J$ Haematol 1978;38:367-71.

${ }^{17}$ Mennemeyer R, Hammer SP, Cathy WJ. Malignant lymphoma with intracytoplasmic IgM crystalline inclusions. $N$ Engl J Med 1974;291:960-3.

18 Van Den Tweel JG, Taylor CR, Parker JW. Immunoglobulin inclusions in non-Hodgkin lymphomas. Am J Clin Pathol 1978:69:306-13.

19 Jenaette JC, Wilkman AS, Benson JD. IgD myeloma with intracytoplasmic crystalline inclusions. Am J Clin Pathol 1982;75:231-5.

${ }^{20}$ Binet JL, Lejorrier M, Dighiere G, et al. A clinical staging system for chronic lymphocytic leukemia. Cancer 1977;40: 855-64.

${ }^{21}$ Schuit HRE, Hijmans W, Asma GEM. Identification of mononuclear cells in human blood. I. Qualitative and quantitative data on surface markers after formaldehyde fixation of the cells. Clin Exp Immunol 1980;41:559-74.

${ }^{22}$ Schuit HRE, Hijmans W. Identification of mononuclear cells in human blood. II. Evaluation of morphological and immunological aspects of native and formaldehyde-fixed cell populations. Clin Exp Immunol 1980;41:567-74.

${ }^{23}$ Van Camp B, Reynaert Ph, Broodtaerts L. Studies on the origin of the precursor cells in multiple myeloma, Waldenström's macroglobulinemia and benign mononuclear gammopathy. Clin Exp Immunol 1981;44:82-9.

${ }^{24}$ Hijmans W, Schuit HRE, Klein F. An immunofluorescence procedure for the detection of intracellular immunoglobulin. Clin Exp Immunol 1969;4:457-72.

${ }^{25}$ Cawley JC, Emmines J, Goldstone AH. Distinctive cytoplasmic inclusions in chronic lymphocytic leukemia. Eur J Cancer 1975;11:91-2.

${ }^{26}$ Kaplan ME, Clark C, Rydell RE. Crystalline IgM inclusions in CLL lymphocytes. Clin Res 1972;20:787-92.

${ }^{27}$ Huhn D, Thiel E, Rodt H. Immunoglobulin-Ablagerungen in Lymphadenose-Zellen. Klin Wochenschr 1975;53:317-20.

${ }^{28}$ Guglielmi P, Preud'homme JL. Unusual intracytoplasmic immunoglobulin inclusions in chronic lymphocytic leukaemia. Br J Haematol 1982;50:123-34.

${ }^{29}$ Preud'homme JL, Seligmann M. Immunoglobulins on the surface of lymphoid cells in Waldenström's macroglobulinemia. J Clin Invest 1972;51:701-8.

${ }^{30}$ Pernis B, Brouet JC, Seligmann M. IgD and IgM on the membrane of lymphoid cells in macroglobulinemia. Evidence for identity of membrane IgD and IgM antibody activity in a case with anti-IgG receptors. Eur J Immunol 1974:4:776-84.

${ }^{31}$ Fu SM, Winchester PJ, Walzer PD, Kunkel HG. Idiotype specificity of surface immunoglobulin and the maturation of leukemic bone marrow derived lymphocytes. Proc Natl Acad Sci USA 1974;71:4487-91.

${ }^{32}$ Schroer KR, Briles DE, Van Boxel JA, Davie JM. Idiotypic uniformity of cell surface immunoglobulin in chronic lymphocytic leukemia. J Exp Med 1974;140:1416-21.

${ }^{33}$ Sugai S, Hirose Y, Konaka Y, Konda S. Leukemic lymphosarcoma (LLS) with monoclonal IgM: idiotype specificity on the cell surface and the cytoplasm of lymphosarcoma cells. Blood 1978;52:922-99.

${ }^{34}$ Vogler LB. Bone marrow B-cell development. Clin Hematol 1982;11(3):509-29.

${ }^{35}$ Van Camp B. Clinical and experimental studies on the nature of monoclonal gammopathies. Academic thesis, Brussels: VUB, 1980.

${ }^{36}$ Van Camp B, Thielemans C, De Waele M. Non-Hodgkin lymphomas, M Kahler and Waldenström. In: Engelfriet CP, von dem Borne AFG, Van Loghem JJ, eds. Research monographs in immunology Vol: Immunohematology (in press).

${ }^{37}$ Speckart SF, Boldt DH, MacDermott RP. Chronic lymphatic leukemia: cell surface changes detected by lectin binding and their relation to altered glycosyltransferase activity. Blood 1978;52:681-95.

${ }^{38}$ Roberts GH, Gordon J, Smith JL, Newell D, Pike R. Biosynthesis and characterisation of IgM-lambda in a case of chronic lymphocytic leukemia with intracellular immunoglobulin inclusions. J Clin Pathol 1979;32:271-9.

Requests for reprints to: Dr O Peters, AZ-VUB Department of Hematology, Laarbeeklaan 101, B-1090 Brussels, Belgium. 